\title{
Management of Subsidence in a Potash Mining Area
}

\author{
Lluís Sanmiquel $^{\mathbf{1}}$, Marc Bascompta ${ }^{1}$, Jordi Vives ${ }^{2}$, José Juan de Felipe ${ }^{2}$ \\ ${ }^{1}$ ICL Chair in Sustainable Mining. Polytechnic University of Catalonia (UPC) \\ Avenue Bases de Manresa, 61-73, 08242-Manresa, Barcelona, Spain \\ lluis.sanmiquel@upc.edu; marc.bascompta@upc.edu \\ ${ }^{2}$ Department of Mining Engineering, Industrial and ICT, Polytechnic University of Catalonia (UPC) \\ Avenue Bases de Manresa, 61-73, 08242-Manresa, Barcelona, Spain \\ jordi.vives@upc.edu; jose.juan.de.felipe@upc.edu
}

\section{Extended Abstract}

Potash mining is an important economic activity in the region of Catalonia (Spain), where there are two mines in Sallent and Súria. The extraction levels are between a depth of 500-1000 meters. This extraction generates surface horizontal and vertical displacements, which was controlled by periodic GPS measurements in permanent points. Each mine was surveyed every two years, having measurements from 2008 to 2016 through 600 control points. This system has been modified to only 200 control points and the support of an interferometric SAR methodology. The main goal of this study was to create a subsidence management system for both mines. In fact, the management of subsidence has increased in importance over the last two decades [1-3] and different studies have reported procedures to be applied. However, there is no standardized procedure identified, since the trend is that each engineer uses an "in-house" method [1] adapted to each specific case. A system was created by means of the software ArcGIS to achieve an effective management of the subsidence evolution over the time, taking into account the main factors of subsidence: horizontal and vertical displacement, module, orientation, direction and velocity of the displacement, The GIS has been proved as an appropriate tool to manage and control subsidence in a user-friendly system with a high easy visual understanding of the subsidence effects and flexibility to introduce new variables of combine it with other software.

\section{References}

[1] D. Scott and C. J. Anumba, "A knowledge-based system for the engineering management of subsidence cases," The Structural Engineer, vol. 77, no. 3, pp. 26-31, 1999.

[2] H. J. Oh and S. Lee, "Integration of ground subsidence hazard maps of abandoned coal mines in Samcheok, Korea," International Journal of Coal Geology, vol. 86, no. 1, pp. 58-72, 2011.

[3] J. Yin, D. Yu, and R. Wilby, "Modelling the impact of land subsidence on urban pluvial flooding: A case study of downtown Shanghai, China," Science of the Total Environment, vol. 544, pp. 744-753, 2016. 